\title{
Doxorubicin Depuration in Oncological Wastewaters Using an Electrochemical Method
}

\author{
DANIELA CRISNIC ${ }^{1}$, VALENTIN ORDODI ${ }^{2,3 *}$, DANIEL HADARUGA ${ }^{2}$, \\ ANAMARIA TODEA ${ }^{2}$, VIRGIL PAUNESCU ${ }^{1}$, SERBAN NEGRU ${ }^{1}$ \\ ${ }^{1}$ University of Medicine and Pharmacy "V. Babes" Timisoara, 2 Eftimie Murgu Sq.,300041, Timisoara, Romania \\ ${ }^{2}$ Politehnica University of Timisoara, 2 Victoriei Sq., 300006, Timisoara, Romania \\ ${ }^{3}$ SC Natural Ingredients R\&D SRL, 10/1 Tabacari Str., 505200, Fagaras, Romania
}

\begin{abstract}
Doxorubicin is a powerful antineoplastic antibiotic used in modern oncological treatments, constitute noteworthy environmental hazards with a great long-term impact on human health. This paper introduces an electrochemical method with a asymmetric current density laboratory reactor specifically designed to neutralize cytostatic agents from wastewaters. The reactor is based on the principle of anodic electrooxidation and on chemical oxidation via anode-generated chlorine reactive species. The design of this electrochemical reactor facilitates very good (approx. 99\%) neutralization yields for the substance used in this study.
\end{abstract}

Keywords: electrochemical reactor, asymmetric current density, cytostatic drug waste, electrooxidation

\section{Introduction}

The modern treatment of oncological diseases use of large quantities of various antineoplasic agents. Antitumoral antibiotics is a class of oncological therapeutical drugs, of which doxorubicin is a member, displays carcinogenic, teratogenic and mutagenic properties. Medical health institutions that offer oncological treatments generate significant quantities of wastewater that contain this type of pollutant, which, if not disposed of properly, can build up in the environment and become hazardous to human and animal health $[1,2]$.

The Romanian legislation stipulates that elimination of these waste materials should be done by incineration, but incineration is a very energy-inefficient process which requires special filters for combustion product evacuation (which can contain dioxins, furanes and gases such as $\mathrm{CO}, \mathrm{CO}_{2}, \mathrm{HCl}$, $\mathrm{SO}_{2}, \mathrm{NO}_{\mathrm{x}}$, etc) and is difficult to apply for very large quantities of liquid waste such as wastewater. Internationally, there have been many proposed methods for inactivating cytostatic drugs in wastewater, but usually they imply the use of concentrated acids and bases and are cumbersome to deploy in a hospital environment $[3,4]$.

The scope of this study is to develop a simple and non-polluting electrochemical method adequate for doxorubicin depuration, relying on anodic electrooxidation and chemical oxidation via chlorine reactive species [5,6]. The major advantage of the experimental device presented in this paper is the use of an electrochemical reactor with asymmetrical current densities. Due to the reactor construction particularities, this device facilitates the anodic electro-oxidation reactions. The anodic surface is much larger compared to cathodic surface, and this favors predominantly this type of electro-oxidation reactions, thus minimizing the reduction cathodic reactions. The method presented in this study, used for inactivation of cytotoxic waste, is much effective compared to literature data [7-9], which describe electrochemical reactors with equal surfaces for both anode and cathode, which do not favor the anodic electro-oxidation reactions.

*email: valichem22@gmail.com 


\section{Materials and methods}

The experimental device consist is an asymmetric current density laboratory reactor. Is comprised of a Berzelius glass with working volume $100 \mathrm{~mL}$. The Berzelius glass is covered with a polypropylene cap in which four graphite anodes are mounted circularly and a stainless-steel cathode located centrally. The cathode active surface is $3.8 \mathrm{~cm}^{2}$, and the anode active surface is $23.1 \mathrm{~cm}^{2}$. The current density for cathode is $1315 \mathrm{~A} / \mathrm{m}^{2}$, and for anode is $216 \mathrm{~A} / \mathrm{m}^{2}$ in our experimental conditions with total current 500 $\mathrm{mA}$. There is also a hole with a diameter of $1 \mathrm{~cm}$ for sampling during the operation of the electrochemical reactor (sampling port).

The reactor is designed to have an unequal anode and cathode surface. Anode surface is significantly larger than the cathode surface, producing a higher cathode current density, thus favoring anodic electrooxidation processes, which further induce degradation of organic substrates. The working current is 500 $\mathrm{mA}$ for each experiment. The homogenization of the reaction mass is provided by a magnetic stirrer. Figure 1 presents the experimental device, and the schematic arrangement of the electrodes [10-12].

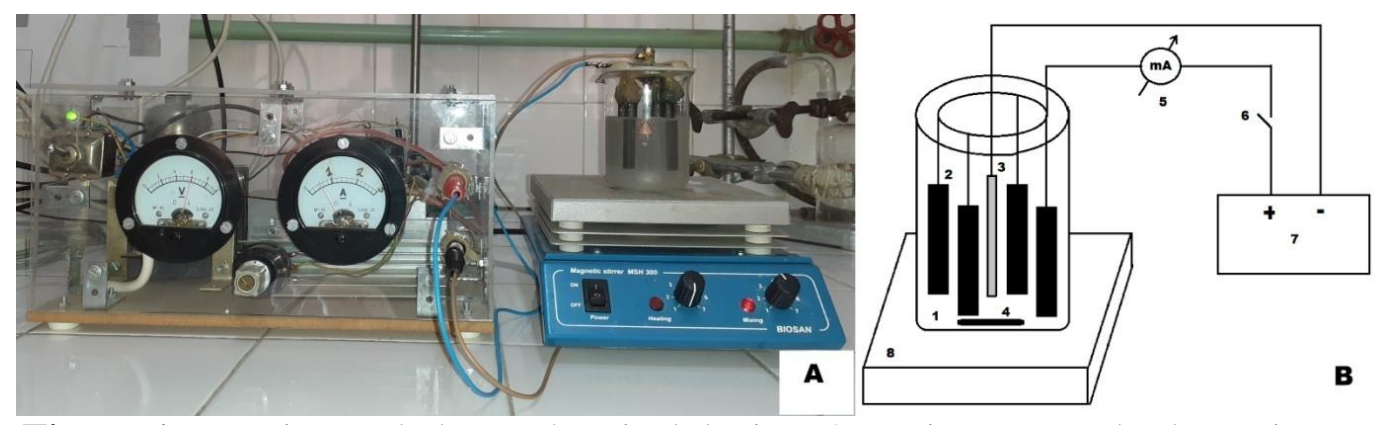

Figure 1.Experimental electrochemical device. Overview (A) and schematic (B).

(1 - Berzelius glass, 2 - Graphite anode, 3 - Stainless steel cathode, 4 - Magnetic bar,

5 -Miliammeter, 6 - Power switch, 7 - Constant current power supply, 8 - Magnetic stirrer)

The doxorubicin - containing sample $(80 \mathrm{~mL})$ is introduced in the electrochemical experimental reactor and starts the electrolysis reaction at room temperature and continuous stirring. The duration of the electrolysis reaction is $30 \mathrm{~min}$ with a constant current of $500 \mathrm{~mA}$.

\section{Synthetic doxorubicin - containing wastewater neutralization}

Doxorubicin is an anthracycline synthesized by Streptomyces Peucetiu, having a planar anthraquinone nucleus attached to an amino sugar. It is an antitumor antibiotic. The molecular formula of doxorubicin is: $\mathrm{C}_{27} \mathrm{H}_{29} \mathrm{NO}_{11}$, named IUPAC: (8S, 10S) -10- (4-amino-5-hydroxy-6-methyltetrahydro-2H-pyran-2-yloxy) -6,8,11- trihydroxy-8- (2-hydroxyacetyl) -1-methoxy-7,8,9,10tetrahydrotetracene-5,12-dione.

Doxorubicin is a red crystalline powder soluble in water. For this study, a synthetic wastewater preparation was made by dissolving 10mg of doxorubicin hydrochloride in $100 \mathrm{~mL} 1 \% \mathrm{NaCl}$ solution. The analytical determination of doxorubicin concentration before and during the electrochemical depuration was made using a fluorimeter - FL 600 Microplate Fluorescence Reader fitted with an excitation filter at $485 \mathrm{~nm}$, and emission filter at $530 \mathrm{~nm}$. All determinations are made in 96-well plates.

Prior the fluorimetric measurement, all samples were treated with a 5\% sodium thiosulphate solution for neutralizing the traces of free chlorine that compromise the results of analytical determinations. For this purpose, $900 \mu \mathrm{L}$ of sample is mixed with $100 \mu \mathrm{L}$ sodium thiosulphate solution in a $1.5 \mathrm{~mL}$ Eppendorf tube. The samples thus prepared are kept in the refrigerator until the moment of analysis.

The operating parameters of the electrochemical reactor have been optimized based on previous experiments. The main purpose of this study was to optimize the electrochemical reactor parameters, so that we achieve the green mode of deployment. The concentration of $1 \% \mathrm{NaCl}$ solution is the minimum required for an accurate reaction speed and minimal electrical power consumption. 
The intensity of electrolysis current was maintained constantly in all the experiments and was established at a minimum value of $500 \mathrm{~mA}$, which does not allow exacerbated heating of support electrolyte, thus avoiding elimination of cytotoxic aerosols by evaporation [13].

\section{Results and discussions}

The putative mechanism for this electrodegradation cascade is presented in Figure 2.<smiles>COc1cccc2c1C(=O)c1c(O)c3c(c(O)c1C2=O)C[C@@](O)(C(=O)CO)C[C@H]3OC1C[C@H](N)[C@@H](O)CO1</smiles>

(8S,10S)-10-((2R,4S,5S,6S)-4-amino-5-hidroxi6-metiltetrahidropiran-2-ioxi)-6,8,11-trihidroxi-8 (2-hidroxiacetil)-1-metoxi-7,8,9,10tetrahidronaftacen-5,12-diona

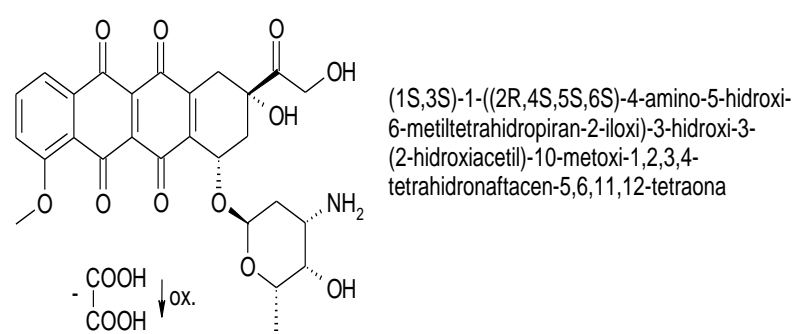<smiles>COc1cccc2c(=O)c3c(=O)c4c(c(=O)c=3c(=O)c12)CC(=O)CC4=O</smiles><smiles>CC(O)CC(C)NC(C)CC(C)O</smiles>
$\mathrm{O}$ " $\mathrm{OH}$-metiltetrahidropiran-2,5-diol $\downarrow$ ox.

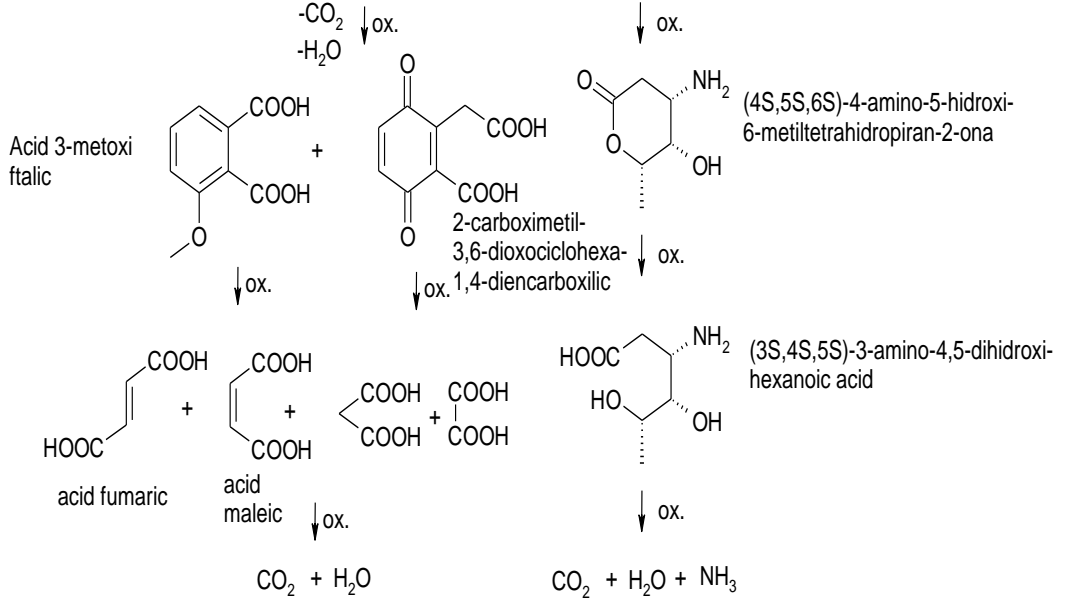

Figure 2. Doxorubicin degradation via electrochemical oxidation

For the quantitative determinations, a calibration curve was drawn using six concentrations of doxorubicin in $1 \% \mathrm{NaCl}$. Prior the fluorimetric measurement, all samples were treated with a $5 \%$ sodium thiosulphate solution according to the protocol described for samples subjected to electrochemical treatment. In Figure 3 the graph of this curve is shown.

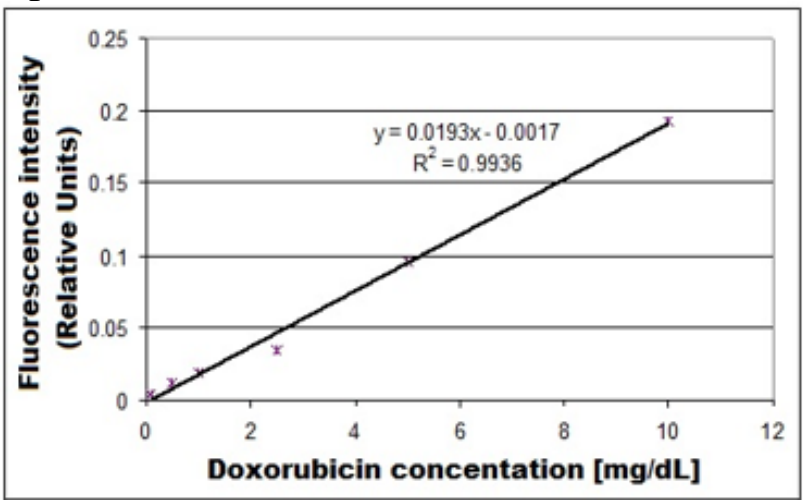

Figure 3. Calibration curve of doxorubicin 
The synthetic wastewater sample containing $10 \mathrm{mg} / \mathrm{dL}$ doxorubicin has undergone electrodegradation in the experimental electrochemical reactor for 30 minutes at $500 \mathrm{~mA}$ working current. The wastewater doxorubicin concentration was sampled during the electrochemical treatment and the samples were analyzed using the fluorimetric method. The results are displayed in Table 1.

Table 1. Fluorimetric analysis of doxorubicin-containing synthetic wastewater during electrochemical depuration

\begin{tabular}{ccc}
$\begin{array}{c}\text { Sampling time } \\
\text { (minutes) }\end{array}$ & $\begin{array}{c}\text { Doxorubicin signal } \\
\text { [Relative Units] }\end{array}$ & $\begin{array}{c}\text { Doxorubicin } \\
\text { concentration } \\
\text { (mg/dl) }\end{array}$ \\
\hline 0 & 0.1916 & 10 \\
1 & 0.1289 & 6.73 \\
2 & 0.0456 & 2.38 \\
3 & 0.0226 & 1.18 \\
4 & 0.0210 & 1.1 \\
5 & 0.0136 & 0.71 \\
10 & 0.0040 & 0.21 \\
15 & 0.0012 & 0.06 \\
30 & $<$ LOD & - \\
\hline
\end{tabular}

In Table I, the evolution of doxorubicin concentration can be observed during electrochemical depuration, dropping below the limit of detection (LOD) of the fluorimeter after 15 minutes. In Figure 4 the graph of the concentration is shown with respect to time, closely approximating a decaying exponential function (Equation 1):

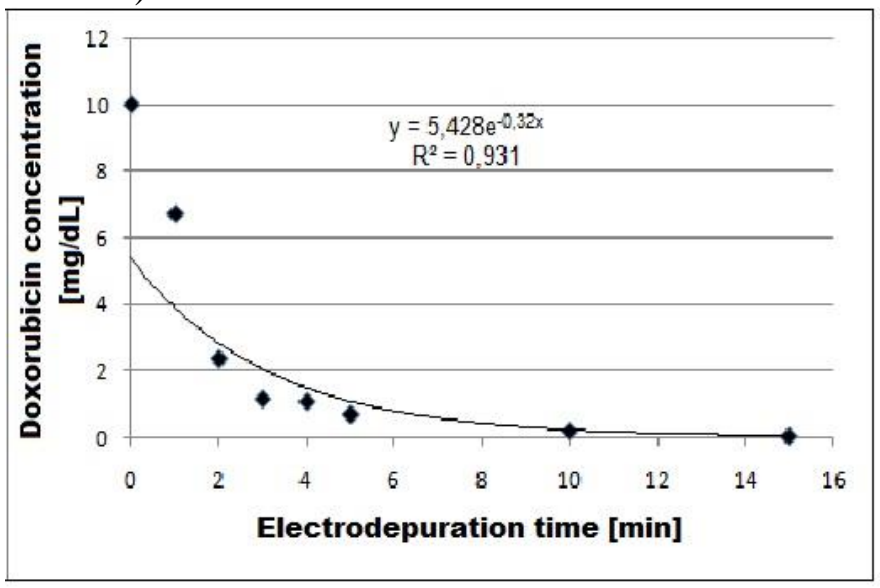

Figure 4. Doxorubicin concentration in synthetic wastewater during the electrodegradation process

$$
\text { doxorubicin }\left(\frac{m g}{d L}\right)=5,428 * e^{-0.32 * t i m e(\text { minutes) }}
$$

The value of the correlation coefficient $\left(R^{2}=0.931\right)$ indicates that equation (1) reliably approximates the evolution of the doxorubicin concentration during electrodegradation [14-16].

The yield of the degradation (2) was calculated using the initial concentration $\left(C_{i}\right)$ of the synthetic wastewater before treatment and the final concentration $\left(C_{f}\right)$ at 15 min into the degradation treatment, right before the concentrations drops below the limit of detection:

$$
\eta_{\text {doxorubicin }}=100-\frac{C f}{C_{i}} * 100=100-0.6=99.4 \%
$$

Doxorubicin is therapeutically effective in the various neoplastic diseases: lymphoblastic leukemia, acute myeloblastic leukemia, Wilms tumors, neuroblastoma, osteosarcomas and soft tissue sarcomas, breast, ovarian, pulmonary carcinoma, bladder carcinoma, biliary carcinoma, thyroid carcinoma. High doses of doxorubicin are administered in intermittent chemotherapy: $100 \mathrm{mg} / \mathrm{m}^{2}$ in patients with advanced breast cancer. Pharmacokinetics data suggests that $40-50 \%$ of administered doxorubicin is 
excreted non-metabolized form, via biliary excretion and 5 - 12\% via renal excretion, which gives the feces and urine of this patients a high concentration of this antineoplastic drug. Literature data has showed that doxorubicin has genotoxic, mutagenic and carcinogenic effects in chronic exposure, even at low doses [17,18].

The experimental data shows that the proposed electrochemical method is suitable for doxorubicin electrodegradation within a reasonable time frame and ecological way.

\section{Conclusions}

The proposed electrochemical method is suitable for doxorubicin-contaminated wastewater treatment. Conceptually, the type of electrochemical reactor used in this paper has the advantage of facilitating the type of reactions we are interested in - anodic electrooxidation. This study recommends the proposed electrochemical method for depuration of wastewater from oncological medical and research institutions.

\section{References}

1.***INTERNATIONAL AGENCY FOR RESEARCH ON CANCER, IARC Monograph on the Evaluation of Carcinogenic Risks to Humans: Listof IARC Evaluations. IARC Lyon, France, 1996

2.HIROSE J., KONDO F., NAKANO T., KOBAYASHI T., HIRO N., ANDO Y., TAKENAKA H., SANO K. Inactivation of antineoplastics in clinical wastewater by electrolysis. Chemosphere, 2005; 60(8): 1018.

3.***HG 1862/2005 for the approval of the project „Incineration of dangerous wastes and sterilization of the wastes resulting from medical activities".

4.VASILESCU V.G., VASILESCU E. Medical wastes - generation, management and ecological elimination. AGIR Bulletin no. 1/2017, 275-279.

5.ORDODI V.L., DUMITREL G.A., ALEXANDRA GRUIA A.T., IACOB M., JINESCU G., PERJU D.M. Electrochemical Microinstallation for Cytostatic Wastes Epuration. Rev. Chim, 61(9), 2010, 857-861.

6.MIRICA M.C., PREDA M., MIRICA N. Theory of electrochemical reactors with asymetric current densities. Mirton Ed. Timisoara, 2006: 109.

7.ANTROPOV L.I. Theoretical electrochemistry, University Press of the Pacific, Honolului Hawaii, 2001.

8.PICKETT D.J. Electrochemical reactor design, Elsevier, Amsterdam, 1979.

9.KERWICK M.I., REDDY S.M., CHAMBERLAIN A.H.L., HOLT D.M. Electrochemical disinfection, an environmentally acceptable method of drinking water disinfection? Electrochimica Acta, 2005; 50: 5270-77.

10.PERJU D., SUTA M., RUSNAC C., BRUSTUREAN G.A. Contributions to the heat transfer study using analogue-digital systems. Rev. Chim., 54(3), 2003, 250-255.

11.KOBAYASHI T., HIROSE J., SQNO K., HIRO N., IJIRI Y., TAKIUCHI H., TAMAI H., TAKENAKA H., TANAKA K., NAKANO T. Evaluation of an electrolysis apparatus for inactivating antineoplastics in clinical wastewater. Chemosphere, 2008; 72(4): 659.

12.KUNISHA YOSHIDA. Electrooxidation in Organic Chemistry, Krieger Publishing Company, Malabar Florida 1993.

13.BRADLEY J.M. Electrolytic destruction of urea in dilute chloride solution using DSA electrodes in a recycled batch cell. Water Res. 2005; 39: 2245-52.

14.KERWICK M.I., REDDY S.M., CHAMBERLAIN A.H.L., HOLT D.M. A methodology for the evaluation of disinfection technologies. J Water Health. 2005 Dec;3(4):393-404.

15.SCIALDONE O., RANDAZZO S., GALIA A., SILVESTRI G. Electrochemical oxidation of organics in water: role of operative parameters in the absence and in the presence of NaCl. Water Res. 2009; 43(8): 2260-72. 16.BRUSTUREAN G.A, TODINCA T., PERJU D., CARRE J., RUSNAC C. Soil vapor extraction of synthetic gasoline mixture: experimental observations and model predictions. Rev. Chim., 58(12), 2007, 1268.

17.DOXORUBICIN HYDROCLORIDE. National Cancer Institute https://www.cancer.gov/aboutcancer/ treatment/drugs/doxorubicinhydrochloride

18.PUGAZHENDHI A., EDISON T.N.J.I., VELMURUGAN B.K., JACOB J.A., KARUPPUSAMY I. Toxicity of Doxorubicin (Dox) to different experimental organ systems. Life Sci. 2018 May 1; 200:26-30.

$\overline{\text { Manuscript received: } 8.04 .2019}$ 